\title{
Volcano Plots and Effective Reversible Potentials for Oxygen Electroreduction
}

\author{
Alfred B. Anderson \\ Published online: 9 March 2012 \\ (C) The Author(s) 2012. This article is published with open access at Springerlink.com
}

\begin{abstract}
It has recently been found that there are ideal values for $\mathrm{O}, \mathrm{OH}$, and $\mathrm{OOH}$ Gibbs adsorption bond strengths to a catalyst that will allow each electron transfer step to have $1.23 \mathrm{~V}$ for its reversible potential. In the case of $\mathrm{Pt}(111)$, the bond strengths are too high by $\sim 0.9 \mathrm{eV}$ for $\mathrm{O}$ and $\sim 0.7 \mathrm{eV}$ for $\mathrm{OH}$ and too small by $\sim 0.4 \mathrm{eV}$ for $\mathrm{OOH}$. These discrepancies result in $\mathrm{OOH}(\mathrm{ads})$ dissociation to $\mathrm{O}$ (ads) $+\mathrm{OH}(\mathrm{ads})$ being $\sim 1.2 \mathrm{eV}$ exergonic. The lost Gibbs energy causes the reversible potential for the four-electron reduction on $\mathrm{Pt}(111)$ to have a value of $\sim 0.9 \mathrm{~V}$, which is called the effective reversible potential. Volcano plots of activity measured at around $0.9 \mathrm{~V}$ depend on the adsorption energies scaling, that is, if one increases they all increase, or if one decreases they all decrease. Volcano plots have been drawn for several transition metal catalysts and platinum and platinum alloy catalysts in the pioneering work of Appleby, Mukerjee, and Adzic and have been seen by many other workers. Although they allow grading the active catalysts in the high overpotential region where reduction current flows, they do not point the direction to better catalysts that will operate at potentials approaching $1.23 \mathrm{~V}$. The search should be for new catalysts which with the right balance of $\mathrm{OOH}, \mathrm{O}$, and $\mathrm{OH}$ adsorption energies.
\end{abstract}

Keywords Effective reversible potentials - Activation energies - Volcano plots Platinum alloys - Theory of electrochemical interface

\footnotetext{
A. B. Anderson $(\triangle)$

Department of Chemistry, Case Western Reserve University, 10900 Euclid Avenue,

Cleveland, OH 44106-7078, USA

e-mail: aba@cwru.edu

\section{Introduction}

In the fuel cell literature, great emphasis is given to kinetics in describing the causes of overpotentials. There is, however, another dimension to understanding the overpotentials and this may be thought of as a thermodynamic factor, the loss of Gibbs energy for reaction steps during which no transfer of electrons takes place. The purpose of this paper is to first describe the kinetic characterization of oxygen cathodes by means of volcano plots and then to describe the thermodynamic factor and then finally to show how they are interrelated. In the process of accomplishing these goals, some of the frontier experimental publications will be discussed, including those of Adzic, to whom this issue is dedicated. It will be shown that the platinum-based catalysts whose activities are often graphed showing volcanos in activity as functions of $\mathrm{O}$ or $\mathrm{OH}$ adsorption energies are constrained to have low effective reversible potentials for four-electron oxygen reduction because, on them, when the $\mathrm{O}$ or $\mathrm{OH}$ adsorption bond strength decreases, the $\mathrm{OOH}$ adsorption bond strength must also decrease for there to be a volcano relationship. However, for the effective reversible potential to increase to the standard value $1.23 \mathrm{~V}$, the $\mathrm{OOH}$ adsorption bond strength must instead increase. This means catalysts with different adsorption properties must be found if the working potentials oxygen cathodes are to increase beyond those observed with platinum and its alloys that have been studied so far.

\section{Volcano Plots and Electrode Surface Site Blocking}

There are two components to the standard understanding of electron transfer reaction rates, and they reside in the 
Arrhenius formula for the reaction rate at potential $U$ for the limiting step in the overall reaction:

$\operatorname{rate}(U)=A(U) \mathrm{e}^{-E_{\mathrm{a}}(U) /(R T)}$.

The preexponential factor, $A(U)$, depends on active adsorption site blocking by electrolyte components or reaction intermediates and the activation energy, $E_{\mathrm{a}}(U)$, could be for displacing the blocking species, for an electron transfer reaction on the electrode surface, or for a non-electron transfer step on the surface. On methanol anodes made of platinum, $\mathrm{CO}$ (ads) requires the anode to operate at high overpotential so that its surface concentration is kept at a low enough level. It is viewed as a blocking specie or surface poison. The anode in hydrogen fuel cells is also susceptible to $\mathrm{CO}$ (ads) poisoning when impurities are involved. However, in hydrogen fuel cells, the greater potential drop is for the oxygen platinum cathode half-cell, and this is the topic of this paper.

In recent years, it has become well-established that platinum electrodes immersed in acidic or basic aqueous electrolytes react with water when the potential is increased from the edge of the hydrogen under potential deposition potential region, $\sim 0.35 \mathrm{~V}$ on the reversible hydrogen electrode scale, which will be used in this paper, to around $0.6 \mathrm{~V}$. At $0.6 \mathrm{~V}$, water begins to be oxidized to $\mathrm{OH}(\mathrm{ads})$, and at around $0.8 \mathrm{~V} \mathrm{OH}(\mathrm{ads})$, it begins to be oxidized to $\mathrm{O}$ (ads) [1-3]. Even before the careful work in these recent references, it was well-known that water oxidizes on platinum cathodes in acid or base as the potential is increased out of the double-layer region, beginning around $0.6 \mathrm{~V}$. It has been long assumed that these adsorbates control the kinetics and current densities of oxygen cathodes by blocking active adsorption sites for $\mathrm{O}_{2}$.

Among the earlier works is a study of Appleby in 1970, who found that the catalytic activity toward the fourelectron reduction of $\mathrm{O}_{2}$ in terms of current densities at a high overpotential, that is, at $-460 \mathrm{mV}$ relative to the standard value of $1.23 \mathrm{~V}$ in $85 \%$ orthophosphoric acid, could be used to create volcano plots [4]. Platinum electrodes were found to be the most active among several transition metal and alloy surfaces studied. They were the peak of current densities at this overpotential when plotted as functions of the Gibbs adsorption energy of $\mathrm{OH}$, a presumed surface poison, and the Gibbs adsorption energy of the presumed $\mathrm{OOH}$ intermediate, whose formation was assigned to be the rate-limiting step:

$\mathrm{O}_{2}+\mathrm{H}^{+}+\mathrm{e}^{-} \rightarrow \mathrm{OOH}(\operatorname{ads})$.

Appleby used transition state theory to show that the effective activation energy over each metal was approximately the Gibbs adsorption bond strength of $\mathrm{OOH}$ on $\mathrm{Pt}$ plus the difference between the adsorption bond strength on the other metal and the adsorption bond strength to Pt. The Gibbs adsorption bond strengths were not available from theory or measurement at the time, so Appleby employed semiempirical relationships of Pauling to estimate the enthalpies of adsorption and these were used in place of the Gibbs adsorption energies. The adsorption energies are negative numbers. $\mathrm{He}$ assumed the $\mathrm{OOH}$ and $\mathrm{O}$ adsorption Gibbs energies were proportional to those for $\mathrm{OH}$ adsorption. In one volcano plot, the assignments of $\mathrm{O}$ atom adsorption Gibbs energies came from the estimated enthalpies of $\mathrm{O}$ atom adsorption and, in two other plots, estimates of percent $\mathrm{d}$ character and d-orbital vacancies of the electrode metals, to which the $\mathrm{OH}$ adsorption Gibbs energies were believed to be related, were used. The volcano effect, with $\mathrm{Pt}$ at the top of activity, was ascribed to a large preexponential factor with high activation energy. The preexponential factor was taken to be a function of surface blocking by $\mathrm{O}$ (ads) and $\mathrm{OH}(\mathrm{ads})$. Metals more electropositive than platinum, for example ruthenium, had smaller activation energies but smaller preexponential factors; and gold, which is more electronegative than platinum, had larger activation energies but its preexponential factors are about the same as the platinum. This interpretation of volcano plots has continued to the present.

Improvements of several tens of millivolts were seen in 1995 by Mukerjee et al. upon comparing Tafel plots for carbon-supported particles of $\mathrm{Pt}-\mathrm{Cr}, \mathrm{Pt}-\mathrm{Mn}, \mathrm{Pt}-\mathrm{Fe}, \mathrm{Pt}-\mathrm{Co}$, and $\mathrm{Pt}-\mathrm{Ni}$ alloys in proton exchange membrane fuel cells [5]. This group produced volcano plots of activity as functions of Pt d-orbital vacancies and nearest neighbor internuclear distances, which were determined, respectively, by in situ by extended X-ray absorption fine structure (EXAFS) and X-ray absorption near-edge structure. Analysis of EXAFS data for the electrocatalysts obtained at 0.54 and $0.84 \mathrm{~V}$ showed no change in surface Pt atom coordination for the alloys, but for pure Pt, the surface Pt atom coordination increased at the higher potential. It was suggested this was due to the bonding of $\mathrm{OH}$ to the surface atoms, which would then block sites for $\mathrm{O}_{2}$ adsorption. This work provided some possible components of an explanation for the observed oxygen reduction kinetics, but a full understanding of the separations between linear Tafel plots they observed over the $\sim 0.82$ to $\sim 0.94-\mathrm{V}$ range could depend on viewing $\mathrm{OH}(\mathrm{ads})$ as a reaction intermediate whose reduction potential needs to be shifted positive for completion of the fourelectron reaction, and not as a blocking agent.

In 2002, Stamenkovic and coworkers prepared electrodes of mildly $\mathrm{Ar}^{+}$-sputtered polycrystalline crystal surfaces of $\mathrm{Pt}_{3} \mathrm{Ni}$ and $\mathrm{Pt}_{3} \mathrm{Co}$ with excess $\mathrm{Pt}$ in the surface layers [6]. These catalysts showed enhanced activity toward $\mathrm{O}_{2}$ reduction when compared to pure Pt polycrystalline electrodes. In $0.1 \mathrm{M} \mathrm{HClO}_{4}$, the sputtered $\mathrm{Pt}_{3} \mathrm{Co}$ was more active, and in $0.5 \mathrm{M} \mathrm{H}_{2} \mathrm{SO}_{4}$, the sputtered $\mathrm{Pt}_{3} \mathrm{Ni}$ was more active. Upon 
annealing, which was believed to produce a monolayer or skin of pure $\mathrm{Pt}$ on the surface of $\mathrm{Pt}_{3} \mathrm{Co}$, the activity was greater than observed for the mildly sputtered $\mathrm{Pt}_{3} \mathrm{Co}$. The enhancements of activities were attributed to reduced formation of site-blocking OH(ads). For the mildly sputtered surfaces, the suggestion was made that $\mathrm{OH}$ or $\mathrm{O}$ bonded to $\mathrm{Ni}$ or Co would weaken the $\mathrm{OH}$ adsorption bond to the intervening active Pt sites, and for the Pt skin, it was suggested that by bonding to the alloy atoms underneath the $\mathrm{Pt}$ sites, the bonding capability of the skin atoms for $\mathrm{OH}$ adsorption was reduced.

In 2004, Roques and I began a series of four VASP slabband density functional studies addressing $\mathrm{OH}(\mathrm{ads})$ reduction on Pt alloy and Pt skin surfaces. The first showed that both $\mathrm{OH}$ and $\mathrm{H}_{2} \mathrm{O}$ bond more weakly to the (111) Pt skin on $\mathrm{Pt}_{3} \mathrm{Cr}$ alloy surfaces, but the weakening was greater for $\mathrm{OH}$, and from this, it was deduced that the shift of the reversible potential for reducing $\mathrm{OH}(\mathrm{ads})$ to $\mathrm{H}_{2} \mathrm{O}(\mathrm{l})$ would be about $110 \mathrm{mV}$ positive [7]. The implication was that the skin surface would be clear of $\mathrm{OH}(\mathrm{ads})$ at $110 \mathrm{mV}$ higher potential than on pure $\operatorname{Pt}(111)$. The shift in Tafel plots observed by Mukerjee was about $40 \mathrm{mV}$ in this case, but there are many reasons to not expect a perfect agreement. The series ended with a study showing the reversible potential for $\mathrm{OH}(\mathrm{ads})$ reduction on Pt skins on Pt-Co alloys increased as the $\mathrm{Co} / \mathrm{Pt}$ ratio increased, reaching a constant value at about $\mathrm{PtCo}_{3}$ [8].

Roques and I reported adsorption bond strengths, which are positive numbers, for which the spectroscopic notation is $D_{\mathrm{e}}$ when zero-point vibrational energies are not included and $D_{0}$ when they are. These are called chemical bond strengths and are the energy it takes to break or dissociate a bond. Later in this paper, it is advantageous to use Gibbs adsorption bond strengths, which are also positive numbers. For these bond strengths, the symbol $D_{\mathrm{G}}$ will be used; $D_{\mathrm{G}}$ includes the zero-point energy.

In 2005, Adzic and coworkers measured enhanced $\mathrm{O}_{2}$ reduction activities at $0.8 \mathrm{~V}$ in $0.1 \mathrm{M} \mathrm{HClO}_{4}$ for electrodes consisting of Pt monolayers on surfaces of single crystal metals of similar atomic size, $\mathrm{Ru}(0001), \operatorname{Ir}(111), \mathrm{Rh}(111)$, $\mathrm{Au}(111)$, and $\mathrm{Pd}(111)$ [9]. Only the $\mathrm{Pt} / \mathrm{Pd}(111)$ electrodes were more active than $\mathrm{Pt}(111)$. Through slab band density functional calculations of the $\mathrm{O}$ adsorption energies on the various surfaces, a volcano plot was formed. These energies were either $-D_{\mathrm{e}}$ or $-D_{0}$, which was not specified, but the difference is small. Correlation of the energy of d-band center with the $\mathrm{O}$ adsorption energy was noted, so the volcano plot could be calculated with either the d-band center energy or the $\mathrm{O}$ adsorption energy on the abscissa. Calculated activation energies for dissociating $\mathrm{O}_{2}$ (ads) to form $2 \mathrm{O}$ (ads) and activation energies for $\mathrm{O}$ (ads) combining with $\mathrm{H}(\mathrm{ads})$ to form $\mathrm{OH}(\mathrm{ads})$ on the various skins when graphed as linear functions of the $\mathrm{O}$ adsorption energies crossed closest to the $\mathrm{Pt} / \mathrm{Pd}(111)$ entry: when the $\mathrm{O}_{2}$ (ads) dissociation activation energy was highest, due to weak $\mathrm{O}$ adsorption bond strength, the activation energy for forming $\mathrm{OH}(\mathrm{ads})$ was lowest because the strength of $\mathrm{O}$ adsorption was reduced more than the strength of $\mathrm{OH}$ adsorption was reduced. This model suggested the volcano plots were due to a balance of two effects. If $\mathrm{OH}(\mathrm{ads})$ stability were used instead of the activation energy for forming $\mathrm{OH}(\mathrm{ads})$ and if the activation energies for forming $\mathrm{OOH}(\mathrm{ads})$ were used instead of the activation energies for dissociating $\mathrm{O}_{2}$, then these substitutions could be tucked into Appleby's model to give his explanation for the volcano effect.

Adzic was especially interested in reducing the amount of platinum that must be used to maintain high activity for oxygen electroreduction and he began exploring core-shell nanocatalysts [10]. This began with monolayers of Pt with $\mathrm{Ir}$, and $\mathrm{Pt}$ with $\mathrm{Ru}$, on $\mathrm{Pd}(111)$. It was found that activity at $0.8 \mathrm{~V}$ was enhanced relative to the pure Pt skin, for skins with as little as about $40 \% \mathrm{Pt}$ and maximum activity occurred for $80 \% \mathrm{Pt}$. Additional experiments were performed with skin alloys consisting of $75 \% \mathrm{Pt}$ and $25 \% \mathrm{Au}, \mathrm{Pd}, \mathrm{Rh}$, $\mathrm{Re}$, and Os. For these, the activity was enhanced for all cases but Au. Using slab-band density functional calculations of adsorption bond energies of $\mathrm{OH}$ at $1 / 4 \mathrm{ML}$ and $1 / 2$ $\mathrm{ML}$ on the $\mathrm{Au}, \mathrm{Pd}$, and $\mathrm{Rh}$ alloys and 1/4 ML O and 1/4 ML $\mathrm{OH}$ on $\mathrm{Re}$ and $\mathrm{Os}$, a linear correlation between current densities at $0.8 \mathrm{~V}$ and adsorbate repulsion energies was found. It was suggested that increasingly weakened $\mathrm{OH}$ or $\mathrm{O}$ adsorption caused the increasing activity.

With the continuing goal of using less platinum and high dispersion of electrocatalysts, the Adzic group turned to synthesizing and testing various transition metal nanosized cores with platinum monolayers on their surfaces [11-13]. Carbon-supported electrocatalysts were synthesized and found to have high activity toward $\mathrm{O}_{2}$ reduction and improved stability compared to Pt under cathode operating conditions. Platinum monolayers on nano-sized $\mathrm{Ru}$ cores had superior $\mathrm{CO}$ tolerance and activity for methanol oxidation at the anode than commercial electrocatalysts [11], and Pt monolayers on nano-sized Pd and Pd alloy cores had superior activity and stability for $\mathrm{O}_{2}$ reduction at the cathode [11-13].

Following the pioneering experimental work sampled so far, there has been an explosion of studies of $\mathrm{O}_{2}$ reduction on new or modified platinum alloy electrocatalysts. These include, for example, the shape effects of $\mathrm{Pt}_{3} \mathrm{Ni}$ polyhedra [14], the effects of near-surface alloying of Pt [15], and the effects of forming Pt skins on nanoporous catalysts impregnated with electrolytes that are hydrophobic and have high $\mathrm{O}_{2}$ solubility [16].

Theorists were becoming more and more interested, and in 2004, Norskov and coworkers performed density functional calculations to obtain adsorption Gibbs energies $-D_{\mathrm{G}}$, 
as data for constructing volcano plots [17]. This should give more definitive understanding than when semiempirically estimated adsorption bond strengths were used as the basis for discussion in Appleby's model in ref. [4], though the influence of electrode potential on the adsorption bond strengths was not included in the model. They made use of an established linear relationship between calculated activation energies, $E_{\mathrm{a}}$, for dissociative chemisorption of $\mathrm{O}_{2}$ on different metal surfaces and the change in internal energy for the reaction

$1 / 2 \mathrm{O}_{2} \rightarrow \mathrm{O}(\operatorname{ads})$.

Oxygen atom adsorption internal energies were calculated for various metal surfaces using the reaction

$\mathrm{H}_{2} \mathrm{O}(g) \rightarrow \mathrm{O}($ ads $)+\mathrm{H}_{2}(g)$

and the activation energies for $\mathrm{O}_{2}$ dissociative chemisorption estimated from them were determined to be negative for all metals studied except $\mathrm{Ag}$ and $\mathrm{Au}$. A rough correlation was found between the $\mathrm{O}$ and $\mathrm{OH}$ adsorption energies, the latter defined as the energy of the reaction

$\mathrm{H}_{2} \mathrm{O}(g) \rightarrow \mathrm{OH}($ ads $)+1 / 2 \mathrm{H}_{2}(g)$.

This is the correlation assumed by Appleby. A volcano plot of activities for the various metals studied was defined where the low activities of $\mathrm{Ag}$ and $\mathrm{Au}$ were ascribed to the high activation energies for dissociating $\mathrm{O}_{2}$ along with the weak adsorption of $\mathrm{OH}$ and the low activities for metals more electropositive than $\mathrm{Pt}$ were ascribed to the strong adsorption of $\mathrm{O}$ and $\mathrm{OH}$. The formation of $\mathrm{OOH}(\mathrm{ads})$ prior to $\mathrm{O}-\mathrm{O}$ bond cleavage was also considered and it was suggested that $\mathrm{OOH}$ (ads) formation dominated the fourelectron reduction on $\mathrm{Pt}$ at potentials less than $0.8 \mathrm{~V}$. Model calculations also suggested that subsurface electropositive transition metal atoms would activate the surface $\mathrm{Pt}$ atoms by weakening the $\mathrm{O}$ adsorption to them, which could account for the enhanced activity observed for alloys of Pt. Roques and I calculated similar behavior for $\mathrm{OH}$ adsorption [7, 8].

Norskov and coworkers generated volcano plots for a number of Pt alloys with Pt monolayer skin surfaces [18]. The volcano plots had the $\mathrm{O}$ adsorption internal energies on the skins minus the $\mathrm{O}$ adsorption internal energy on $\mathrm{Pt}(111)$ for the abscissa. Changes in the $\mathrm{OOH}$ and $\mathrm{OH}$ adsorption Gibbs energies were assumed to follow (scale) with changes in the $\mathrm{O}$ adsorption energy. In a plot of Gibbs energy as a function of reaction coordinate, decreasing values for the $\mathrm{O}$ adsorption Gibbs energy meant the formation of $\mathrm{OOH}(\mathrm{ads})$ was slowed due to its weakening adsorption but at the same time removal of $\mathrm{OH}(\mathrm{ads})$ was speeded up due to its weakening adsorption. The peak of the volcano corresponded to the internal energy change of Eq. (3) being about $0.2 \mathrm{eV}$ greater than on $\mathrm{Pt}$, meaning the adsorption bond is $0.2 \mathrm{eV}$ weaker. At this condition, the decreases in adsorption bond strengths of $\mathrm{OOH}$ and $\mathrm{OH}$ compared to the values on pure $\mathrm{Pt}$ are both $0.1 \mathrm{eV}$. The calculated $\mathrm{O}$ adsorption internal energies on the skins on $\mathrm{Pt}_{3} \mathrm{Y}$ and $\mathrm{Pt}_{3} \mathrm{Sc}$ were in a range for which the model predicted them to be more active than Pt at $0.9 \mathrm{~V}$ and experiments bore this out. However, the onset for current flow on the milliampere scale was still less than $1.0 \mathrm{~V}$, as it is for other Pt skin alloy catalysts. This means all of the catalysts suffered high overpotentials under fuel cell-operating conditions, a property that is true for all metal catalysts reported to date.

\section{Volcano Plots and Effective Reversible Potentials}

The volcano plots of Appleby and the Mukerjee and Adzic groups discussed above and others in the cited literature of the Norskov group were constructed using current densities measured at several hundred millivolt overpotential. At potentials much higher than the $0.77 \mathrm{~V}$ used by Appleby and the $0.90 \mathrm{~V}$ used by Mukerjee, activity toward $\mathrm{O}_{2}$ reduction ceases as defined by current density on the milliampere scale. The improvements due to alloying the platinum rarely surpass several tens of millivolt. This is depicted in Fig. 1.

In a recent paper from the author's lab, a new concept was established - that of effective reversible potential $U_{\text {effective }}^{\text {rev }}$ [19]. It is based on the observation that for any exergonic steps in the reaction which do not include electron transfer, the wasted Gibbs energy will reduce the efficiency of the cell by reducing the amount of external electrical work it can perform:

$U^{\mathrm{rev}}{ }_{\text {effective }}=1.23 \mathrm{~V}-\left[\Delta G_{\mathrm{ex}} /(4 \mathrm{e})\right]$

where $\Delta G_{\text {ex }}$ is the Gibbs energy loss in electron-volts. Any endergonic steps will have activation barriers to overcome thermally, and if these are greater than the ambient $k_{\mathrm{b}} T$,

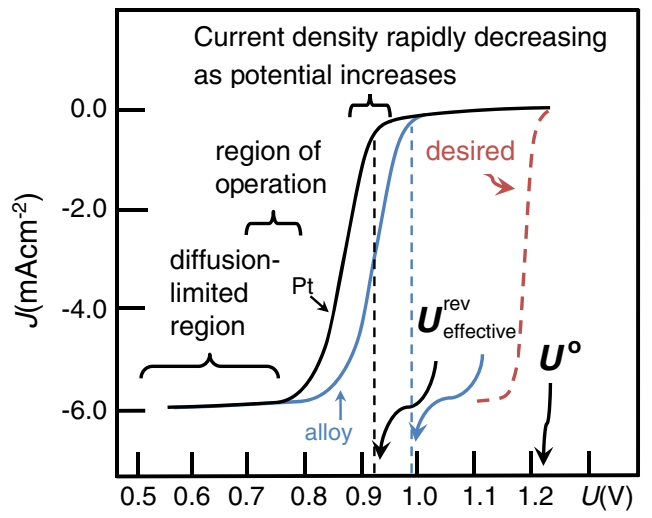

Fig. 1 Schematic polarization curves for $\mathrm{O}_{2}$ reduction on a $\mathrm{Pt}(111)$ electrode (black) and on a high-activity Pt monolayer or skin electrode (blue) and the behavior of an essentially ideal electrocatalyst (red) 
where $k_{\mathrm{b}}$ is the Boltzmann constant, providing the necessary heat will also reduce the efficiency of the power system.

There are three non-electron transfer reaction steps to pass through during the four-electron reduction of $\mathrm{O}_{2}$ on $\mathrm{Pt}(111)$ : (1) $\mathrm{O}_{2}(\mathrm{~g})$ adsorption, displacing $\mathrm{H}_{2} \mathrm{O}$ (ads), calculated to involve a relatively small change in Gibbs energy [20], (2) $\mathrm{OOH}(\mathrm{ads})$ dissociation, calculated to be about $1.2 \mathrm{eV}$ exergonic, and (3) desorption of $\mathrm{H}_{2} \mathrm{O}(\mathrm{ads})$, calculated to have almost no change in Gibbs energy. Using the Gibbs energy loss for the $\mathrm{OOH}(\mathrm{ads})$ dissociation step alone results in the effective reversible potential for four-electron reduction of $\mathrm{O}_{2}: U_{\text {effective }}^{\text {rev }}=1.23 \mathrm{~V}-1.2 \mathrm{~V} / 4=0.93 \mathrm{~V}$. This potential is close to the observed onset potential for $\mathrm{O}_{2}$ reduction over a Pt catalyst, which is seen in polarization curves. Platinum alloy catalysts often have smaller $D_{\mathrm{G}}$ values for the adsorbed intermediates and consequently $U_{\text {effective is at }}^{\text {rev }}$ $\sim 50 \mathrm{mV}$ higher potentials, as shown in Fig. 1. Thus, the limiting overpotential is a thermodynamic effect caused by Gibbs energy loss. If no Gibbs energy was lost during nonelectron transfer steps, $U_{\text {effective }}^{\text {rev }}$ would be $1.23 \mathrm{~V}$, and, with fast kinetics and provided all of the electron transfer steps had $1.23 \mathrm{~V}$ reversible potentials, the red curve in Fig. 1 would be measured. The steepness of the drop is a function of the electron transfer activation energies: the lower they are, the faster the drop as the potential is decreased from $U_{\text {effective. Is }}^{\text {rev }}$ there a condition which makes it possible for all electron transfer steps to take place at $1.23 \mathrm{~V}$ ? The answer is yes.

Based on experimental bulk solution data for $\mathrm{O}_{2}(\mathrm{~g})$ reduction to $\mathrm{OOH}(\mathrm{aq}), \mathrm{O}(\mathrm{aq})$ reduction to $\mathrm{OH}(\mathrm{aq}), \mathrm{OH}(\mathrm{aq})$ reduction to $\mathrm{H}_{2} \mathrm{O}(\mathrm{l})$, and the four-electron reduction of $\mathrm{O}_{2}(\mathrm{~g})$ to $\mathrm{H}_{2} \mathrm{O}(1)$, it was shown in ref. [19] that $U_{\text {effective }}^{\mathrm{rev}}$ for $\mathrm{O}(\mathrm{ads})$ and $\mathrm{OH}(\mathrm{ads})$ reduction would shift to $1.23 \mathrm{~V}$ if $D_{\mathrm{G}}$ were 2.38 and $1.49 \mathrm{eV}$, respectively, at $1.23 \mathrm{~V}$ for these intermediates, provided the adsorption Gibbs energies of $\mathrm{O}_{2}$ and $\mathrm{H}_{2} \mathrm{O}$ are zero, which is an approximation. From these values, to have the reversible potential for $\mathrm{OOH}(\mathrm{ads})$ formation at $1.23 \mathrm{~V}, D_{\mathrm{G}}$ for $\mathrm{OOH}(\mathrm{ads})$ would have to be $1.35 \mathrm{eV}$ at $1.23 \mathrm{~V}$. It has been shown that the $D_{\mathrm{G}}$ values calculated for the uncharged surface, which is the potential of zero charge (pzc), vary $\sim 0.1 \mathrm{eV}$ or less from the values calculated at $1.23 \mathrm{~V}$ [21]. In the following discussion, pzc values will be used, though this introduces errors of $\sim 0.1$ to $0.2 \mathrm{~V}$. Calculations of $D_{\mathrm{G}}$ on the $\operatorname{Pt}(111)$ surface in the presence of $1 / 2 \mathrm{ML}$ adsorbed water showed that at the pzc they were about $0.88 \mathrm{eV}$ too large for $\mathrm{O}(\mathrm{ads})$ and $0.66 \mathrm{eV}$ too large for $\mathrm{OH}(\mathrm{ads})$ [21]. It is evident from these numbers that reductions in $\mathrm{O}$ and $\mathrm{OH} D_{\mathrm{G}}$ values will increase $U_{\text {effective }}^{\text {rev }}$ decreasing the Gibbs energy loss that accompanies dissociation of the $\mathrm{O}-\mathrm{O}$ bond in $\mathrm{OOH}(\mathrm{ads})$. However, decreasing $D_{\mathrm{G}}$ for $\mathrm{OOH}(\mathrm{ads})$ will serve to reduce this increase in $U_{\text {effective. Such reductions will also change the reversible }}^{\text {rev }}$ potentials for $\mathrm{O}(\mathrm{ads})$ reduction to $\mathrm{OH}(\mathrm{ads})$ and for $\mathrm{OH}(\mathrm{ads})$ reduction to $\mathrm{H}_{2} \mathrm{O}(1)$. For example, if the calculated $D_{\mathrm{G}}$, $3.26 \mathrm{eV}$, is used for $\mathrm{O}(\mathrm{ads})$ and the ideal $D_{\mathrm{G}}, 1.49 \mathrm{eV}$, is used for $\mathrm{OH}(\mathrm{ads})$, the reversible potential would be $0.35 \mathrm{~V}$, which is $0.88 \mathrm{~V}$ low. On the other hand, if the ideal value, $2.38 \mathrm{eV}$, is used for $\mathrm{O}$ (ads) and the calculated value, $2.15 \mathrm{eV}$, is used for $\mathrm{OH}$ (ads), the prediction is $1.89 \mathrm{~V}$, which is $0.66 \mathrm{~V}$ high. The value of $D_{\mathrm{G}}$ for $\mathrm{OOH}(\mathrm{ads})$ is around $0.45 \mathrm{eV}$ too weak on $\mathrm{Pt}$ (111) (Anderson and Udin, unpublished results), so improved catalysts that adsorb $\mathrm{O}(\mathrm{aq})$ and $\mathrm{OH}(\mathrm{aq})$ more weakly than $\mathrm{Pt}$ must at the same time adsorb $\mathrm{OOH}(\mathrm{aq})$ more strongly if $U_{\text {effective }}^{\text {rev }}$ is to shift all the way to $1.23 \mathrm{~V}$. This runs into conflict with the above-mentioned interpretations given to volcano plots where it was assumed that $\mathrm{OOH}$ and $\mathrm{O}$ adsorption internal energies would both increase when the $\mathrm{O}$ adsorption energy increased. The implications of the necessary decrease in $D_{\mathrm{G}}$ for $\mathrm{OOH}(\mathrm{ads})$ are significant, as will be shown in the following.

Appleby's qualitative formula for current density depended on the assumption that $D_{\mathrm{G}}$ for $\mathrm{OOH}$ is proportional to that for $\mathrm{OH}$, and this explained the volcano plots. Appleby assumed the $\mathrm{O}$ adsorption bond strength was proportional to that for $\mathrm{OH}$ and a volcano plot was shown for current density versus $\mathrm{O}$ adsorption energy. The Norskov group confirmed the Appleby model by using theoretical calculations to show that the adsorption energies of $\mathrm{OOH}$, $\mathrm{OH}$, and $\mathrm{O}$ increase together and decrease together and used the results to make volcano plots. One way to think of their presentation in ref. [18] is the following: If for a series of catalysts with similar adsorption properties one is most active at some potential, such as $0.9 \mathrm{~V}$, then at any nearby potential, the activation energy for $\mathrm{OOH}$ (ads) formation from $\mathrm{O}_{2}$ or $\mathrm{OH}(\mathrm{ads})$ reduction to $\mathrm{H}_{2} \mathrm{O}$ will control the rate for this catalyst and the controlling activation energy is a nadir for the activation energies of all the catalysts in the group making up the volcano plot.

Results of detailed, but approximate, Gibbs energy calculations were used in kinetic equations by Jinnouchi and coworkers to generate volcano plots for 11 Pt-based model catalysts based on $\mathrm{O}$ adsorption energies and good qualitative agreement was seen with reported experimental literature [22]. The scaling of adsorption bond strengths held for the catalysts they studied.

Explicitly calculated electron transfer activation energies can also be used to explain the volcano behavior. The shapes of calculated oxidation and reduction activation energy curves as functions of the electrode potential are fairly robust toward changes in adsorption bond strength [23-25]. Figure 2 shows how the activation energy for $\mathrm{OOH}$ (ads) formation will decrease on an ideal catalyst relative to Pt. Activation energies for reduction reactions occurring during $\mathrm{O}_{2}$ reduction to water were calculated to be $\sim 0.1-0.2 \mathrm{eV}$ at the crossing points, which are taken as approximations to the reversible reactions for these 


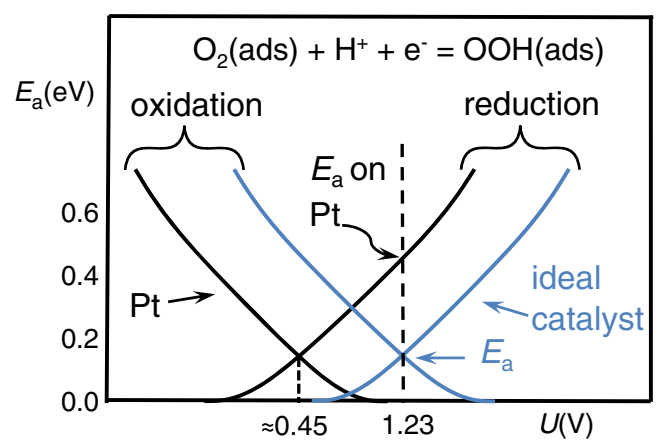

Fig. 2 Schematic depiction of electrode potential dependencies of activation energies for $\mathrm{O}_{2}(\mathrm{ads})$ reduction and $\mathrm{OOH}(\mathrm{ads})$ oxidation on $\mathrm{Pt}$ and on an ideal catalyst for which the reversible potential is $1.229 \mathrm{~V}$, the reversible potential for the four-electron reduction of $\mathrm{O}_{2}(\mathrm{~g})$. The activation energy for each case is indicated by an arrow. Curves are based on calculations in refs. [23-25]

reactions [23-25]. It is not presently possible to calculate highly accurate electrode potential-dependent electron transfer activation energies, but considering the data in refs. [23-25], it is probable that the highest activation barrier is that for $\mathrm{OOH}(\mathrm{ads})$ formation up to a point where $\mathrm{OH}(\mathrm{ads})$ reduction takes over the role of presenting the highest barrier, as shown in Fig. 3. Using the hypothesis, backed by calculations in the literature discussed above, that on $\mathrm{Pt}$ monolayers on Pt alloys and on many other pure metal cores $\mathrm{OOH}, \mathrm{OH}$, and $\mathrm{O}$ adsorb more weakly than on pure $\mathrm{Pt}$, and that the changes are roughly the same for each of these adsorbates, qualitative shifts in the reversible potentials and activation energy curves may be drawn in Fig. 3. In this figure, if the solid black and red lines are, respectively, the activation energies for $\mathrm{OOH}\left(\right.$ ads) formation and $\mathrm{H}_{2} \mathrm{O}(\mathrm{l})$ formation, then the crossing point is at the potential where they are equal. Let the red and black curves represent activation energies for the most active catalyst in a series

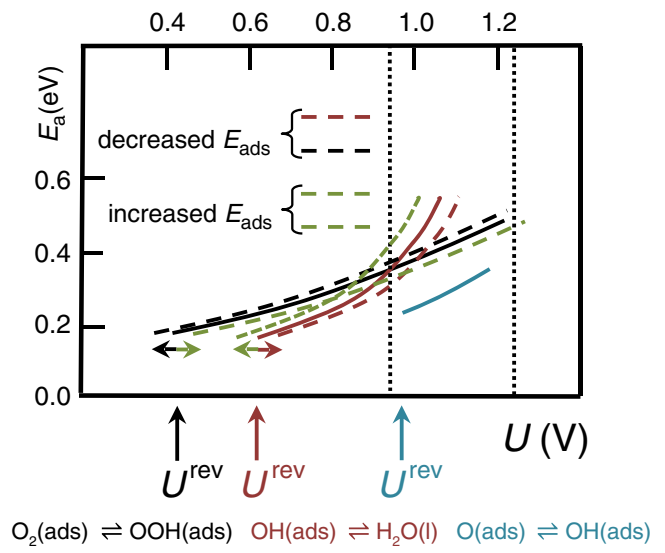

Fig. 3 The solid curves are suggested behaviors for the electrode potential dependencies on $\mathrm{Pt}$ electrodes of reduction activation energies based on the approximate calculated results in ref. [22]. Dashed curves show shifts due to $\sim 0.05 \mathrm{eV}$ decreases and increases in adsorption bond strengths for $\mathrm{OOH}, \mathrm{O}$, and $\mathrm{OH}$ of catalysts for which the main difference between them is the adsorption bond strengths of the intermediates. Focusing on the potential at their crossing, if the adsorption bond strengths of $\mathrm{OOH}$ and $\mathrm{OH}$ on another catalyst are less, then the activation energy for $\mathrm{OOH}$ (ads) formation is higher on this catalyst at this potential, as seen by the intersection of the vertical dotted line with the black dashed line and the activation energy for $\mathrm{H}_{2} \mathrm{O}(\mathrm{l})$ formation decreases: the rate is controlled by the $\mathrm{OOH}(\mathrm{ads})$ formation step. If, on the other hand, the adsorption energies for these species are higher on another catalyst, then the rapidly rising green dashed line shows that the rate is controlled by the $\mathrm{OH}(\mathrm{ads})$ reduction reaction. If the $\mathrm{OH}$ and $\mathrm{O}$ adsorption bond strengths change by about the same amount, the blue line representing $\mathrm{O}$ (ads) reduction to $\mathrm{OH}(\mathrm{ads})$ changes little, but this does not matter because the activation energy for this step is smaller than for the other two.

As $U_{\text {effective }}^{\text {rev }}$ increases, as shown by the tilted arrows in Fig. 4, reduction current densities at a given potential will increase as indicated by the horizontal arrows. How does this behavior relate to volcano plots?

The dissociation reaction

$$
\mathrm{OOH}(\text { ads }) \rightarrow \mathrm{O}(\text { ads })+\mathrm{OH}(\text { ads })
$$

is expected to be less exergonic as the $D_{\mathrm{G}}$ becomes smaller so that $U_{\text {effective }}^{\text {rev }}$ would be expected to increase. However, based on examining voltammograms in the referenced literature, $U_{\text {effective }}^{\text {er }}$ fact reaches a limit at around $1.0 \mathrm{~V}$. The catalysts being studied seem to be stuck in a range mandated by the strong adsorption of the products in Eq. (7). More

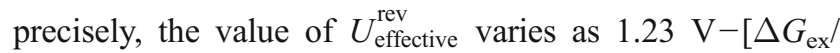
(4e)], where $\Delta G_{\mathrm{ex}}$ is the exergonicity of the reaction Eq. (7). Because $D_{\mathrm{G}}$ for $\mathrm{OOH}(\mathrm{ads})$ and $\mathrm{O}(\mathrm{ads})$ and $\mathrm{OH}$ (ads) desorption apparently all decrease or increase together, the change in reaction energy on a Pt skin is roughly the change in $D_{\mathrm{G}}$ for a single adsorbate. Consequently, the change in $\Delta G_{\mathrm{ex}} / 4$ for the Pt skins relative to pure platinum is not very large for

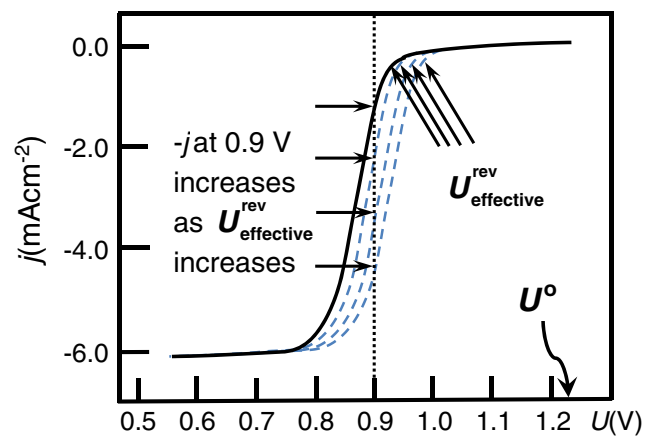

Fig. 4 Series of voltammograms modeling how the current density at a given potential would change as the effective reversible potential, $U_{\text {effective, }}^{\text {rev }}$ changes provided the voltammograms retain their shape 
the platinum-based catalysts studied. If the $D_{\mathrm{G}}$ for O(ads) and $\mathrm{OH}(\mathrm{ads})$ decreased to approach their ideal values of 2.38 and $1.49 \mathrm{~V}$, respectively, then for the reversible potential for forming $\mathrm{OOH}(\mathrm{ads})$ to be $1.23 \mathrm{~V}$, the $\mathrm{OOH}(\mathrm{aq})$ Gibbs adsorption bond strength would have to increase from its low value to $1.35 \mathrm{eV}$, which does not fit the observation that on metal catalysts referenced above according to which the Gibbs adsorption bond strength for $\mathrm{OOH}$ should decrease. To get closer to $1.23 \mathrm{~V}$ for the current onset in polarization curves, it is necessary to find catalysts to which $\mathrm{OOH}$ bonds more strongly and at the same time $\mathrm{O}$ and $\mathrm{OH}$ both bond more weakly than is the case for metal catalysts tried to date. If this is someday accomplished, it may be possible to generate volcano plots for catalysts with these properties when choosing potentials that are much closer to 1.23 than $0.9 \mathrm{~V}$.

\section{Conclusions}

The metallic catalysts used for the four-electron reduction of $\mathrm{O}_{2}$ generally bond the $\mathrm{O}$ and $\mathrm{OH}$ intermediates too strongly to their active sites and this contributes to effective reversible potentials being several hundred millivolts less than the standard reversible potential. When it is assumed that the strength of $\mathrm{OOH}$ bonding to the active site scales with $\mathrm{O}$ and $\mathrm{OH}$, current densities measured at an overpotential in the kinetic current range for a series of catalysts obeying the scaling behavior can be graphed as functions of the adsorption bond strength of any one of the intermediates and, with sufficient data, volcano plots emerge. These plots have been a focus of pioneering work of Appleby, Mukerjee, and Adzic, and in their work and recent work of others, a steady improvement in electrocatalyst activity has emerged. The focus of these workers has been on platinum-based alloys of chosen compositions and structures. If one is to overcome the overpotential problem, it will be necessary for $D_{\mathrm{G}}$ for $\mathrm{O}, \mathrm{OH}$, and $\mathrm{OOH}$ bonding to the catalyst active site to have particular values which seem incompatible with these alloy catalysts. The $D_{\mathrm{G}}$ values for $\mathrm{H}_{2} \mathrm{O}(\mathrm{l})$ and $\mathrm{O}_{2}(\mathrm{~g})$ and the Gibbs energy for $\mathrm{O}_{2}$ displacing $\mathrm{H}_{2} \mathrm{O}$ (ads), if not zero, may affect these particular values by small amounts. The volcano plots depend on scaling of the adsorption bond strengths of the three intermediates. In fact, on Pt (111) bonding of $\mathrm{OOH}$ to the surface is too weak, not too strong, and catalysts with the needed balance of adsorption bond strengths for the intermediates may someday be discovered. Such catalysts will present volcano plots for current densities measured at potentials close to $1.23 \mathrm{~V}$.
Acknowledgments This material is based upon a work supported by the National Science Foundation under grant no. CHE-0809209.

Open Access This article is distributed under the terms of the Creative Commons Attribution License which permits any use, distribution, and reproduction in any medium, provided the original author(s) and the source are credited.

\section{References}

1. V. Climent, R. Gomez, J.M. Orts, J.M. Feliu, J. Phys. Chem. B 110, 11344-11351 (2006)

2. J.X. Wang, J. Zhang, R.R. Adzic, J. Phys. Chem. A 111, 12702 $12710(2007)$

3. M. Wakisaka, H. Suzuki, S. Mitsui, H. Uchida, M. Watanabe, Langmuir 25, 1897-1900 (2009)

4. A.J. Appleby, Catal. Rev. 4, 221-243 (1970)

5. S. Mukerjee, S. Srinivasan, M.P. Soriaga, J. McBreen, J. Electrochem. Soc. 142, 1409-1422 (1995)

6. V. Stamenkovic, T.J. Schmidt, P.N. Ross, N.M. Markovic, J. Phys. Chem. B 106, 11970-11979 (2002)

7. J. Roques, A.B. Anderson, J. Electrochem. Soc. 151, E85-E91 (2004)

8. J. Roques, A.B. Anderson, Surf. Sci. 581, 105-117 (2005)

9. J. Zhang, M.B. Vukmirovic, Y. Xu, M. Mavrikakis, R.R. Adzic, Angew. Chem. Int. Ed. 44, 2132-2135 (2005)

10. J. Zhang, M.B. Vukmirovic, K. Sasaki, A.U. Nilekar, M. Mavrikakis, R.R. Adzic, J. Am. Chem. Soc. 127, 12480-12481 (2005)

11. R.R. Adzic, J. Zhang, K. Sasaki, M.B. Vukmiriviv, M. Shao, J.X. Wang, A.U. Nilekar, M. Mavrikakis, J.A. Valerio, F. Uribe, Top. Catal. 46, 249-262 (2007)

12. J.X. Wang, H. Inada, L. Wu, Y. Zhu, Y.-M. Choi, P. Liu, W.-P. Zhou, R.R. Adzic, J. Am. Chem. Soc. 132, 17298-17302 (2009)

13. K. Sasaki, H. Naohara, Y. Cai, Y.M. Choi, P. Liu, M.V. Vukmirovic, J.X. Wang, R.R. Adzic, Angew. Chem. Int. Ed. 49, 8602-8607 (2010)

14. J. Zhang, H. Yang, J. Fang, S. Zou, Nano Lett. 10, 638-644 (2010)

15. I.E.L. Stephens, A.S. Bondarenko, F.J. Perez-Alonso, F. CalleVallejo, L. Bech, T.B. Johansson, A.K. Jepsen, R. Frydendal, B. P. Knudsen, J. Rossmeisl, L. Chorkendorff, J. Am. Chem. Soc. 133, 5485-5491 (2011)

16. J. Snyder, T. Fujita, M.W. Chen, J. Erlebacher, Nat. Mater. 9, 904 $907(2010)$

17. J.K. Norskov, J. Rossmeisl, A. Logadottir, L. Lindqvist, J.R. Kitchin, T. Bligaard, H. Jonsson, J Phys. Chem. B 108, 17886 17892 (2004)

18. J. Greeley, I.E.L. Stephens, A.S. Bondarenko, T.P. Johansson, H.A. Hansen, T.F. Jaramillo, J. Rossmeisl, I. Chorkendorf, J.K. Norskov, Nat. Chem. 1, 552-556 (2009)

19. F. Tian, A.B. Anderson, J. Phys. Chem. C 115, 4076-4088 (2011)

20. R. Jinnouchi, A.B. Anderson, Phys. Rev. B 77, 245417124541718 (2008)

21. A.B. Anderson, Phys. Chem. Chem. Phys. 14(4), 1330-1338 (2012)

22. R. Jinnouchi, K. Kodama, T. Hatanaka, Y. Morimoto, Phys. Chem. Chem. Phys. 13, 21070-21083 (2011)

23. T. Zhang, A.B. Anderson, J. Phys. Chem. C 113, 3197-3202 (2009)

24. T. Zhang, Ph D Thesis, Case Western Reserve University, (2008)

25. A.B. Anderson, Y. Cai, R. Sidik, D.B. Kang, J. Electroanal. Chem. 580, 17-22 (2005) 